\title{
Trimethoprim resistance in urinary pathogens in northern Scotland: epidemic spread of a resistance plasmid encoding the type Ib trimethoprim-resistant dihydrofolate reductase
}

\author{
HILARY-KAY YOUNG and J.K. HILLYEAR* \\ Department of Biological Sciences, University of Dundee, Dundee DD1 4HN and "Department of Medical \\ Microbiology, Ninewells Hospital and Medical School, Dundee DD1 $9 S Y$
}

\begin{abstract}
Summary. The prevalence of trimethoprim resistance in enterobacterial urinary pathogens from hospitalised patients in the Angus district of northern Scotland $(22.8 \%)$ was twice that found in similar isolates from patients attending general practitioners $(11.2 \%)$. Thirty-three of the 143 trimethoprim-resistant strains were shown to harbour transferable plasmids conferring high-level trimethoprim resistance. In total, 17 different plasmid types were distinguished. Two plasmids, pUK1184 and pUK1185, accounted for $36 \%$ of the trimethoprim resistance plasmids and were shown by restriction endonuclease digestion fingerprints to be closely related to plasmid pUK28, previously demonstrated to be endemic in urinary pathogens in the Edinburgh area. Only $21 \%$ of the plasmids were shown to encode the type Ia trimethoprim-resistant dihydrofolate reductase, whereas $70 \%$ of the trimethoprim resistance plasmids were found to encode the type Ib dihydrofolate reductase. Hybridisation of the trimethoprim resistance plasmids identified in this study with gene probes specific for the integrase genes of transposons $\operatorname{Tn} 7$ and $\operatorname{Tn} 21$ indicates that the dhfrIa is rarely present within $\operatorname{Tn} 7$ or related transposons in these plasmids and may be more prevalent within $\operatorname{Tn} 21$ like transposons. In contrast, with the exception of the two endemic plasmids that harboured the $d h f r I b$ gene within a Tn7-like transposon, the majority of $d h f r I b$ genes were not found to be associated with either Tn7- or Tn21-like structures.
\end{abstract}

\section{Introduction}

Trimethoprim, both alone and in combination with sulphamethoxazole, continues to be used widely for the treatment of urinary tract infections. Resistance to trimethoprim is most commonly mediated by plasmidor transposon-encoded dihydrofolate reductase (DHFR) enzymes which are insusceptible to the inhibitory action of trimethoprim. ${ }^{1}$ To date, a total of 16 different gram-negative bacterial plasmid-encoded DHFRs have been described..$^{2-5}$ The type Ia DHFR, commonly carried within the highly successful transposon $\operatorname{Tn} 7,{ }^{6}$ is generally reported to account for the majority of high-level trimethoprim resistance. ${ }^{7}$ Four other trimethoprim-resistant DHFRs, types Ib, V, VI and VII, share $>60 \%$ DNA sequence homology with each other and the type Ia DHFR. ${ }^{8.9}$ The epidemiology of each of these genes is less well defined. The $d h f r V$ and $V I I$ genes have been reported to occur in bacteria isolated in Europe but at a relatively low frequency. ${ }^{10-12}$ The $d h f r V$ gene was also identified as the major mediator of plasmid-encoded trimethoprim resistance in enterobacterial isolates from Sri Lanka. ${ }^{13}$

Received 18 April 1994; accepted 12 May 1994
The dhfrIa, $V$ and $V I I$ genes have all been identified within integron structures commonly associated with Tn2l-like transposons. ${ }^{8,14,15}$ The $d h f r V I$ gene has so far been identified exclusively within pathogens isolated in South Africa. ${ }^{16}$ The dhfrIb gene, which has been shown to reside within a $\operatorname{Tn} 7$-like transposon, $\operatorname{Tn} 4132,{ }^{9}$ was originally identified within plasmids extracted from urinary pathogens isolated in Edinburgh, Scotland. ${ }^{17}$ Recently, this gene has been shown to be present in gram-negative commensal faecal flora obtained from healthy individuals in Southern India. ${ }^{18}$

In Scotland, several surveys have been conducted on both hospital and general practice isolates. These studies have been restricted to two major cities in the South of Scotland, Edinburgh and Glasgow. ${ }^{19-22}$ As in other parts of Europe, the incidence of plasmidmediated resistance has decreased in both these areas during the 1980s. ${ }^{19-21}$ However, amongst the plasmidmediated trimethoprim resistance, one particular resistance plasmid (R-plasmid), pUK28, was found to dominate and has persisted within hospital isolates, especially in the Edinburgh area. ${ }^{1920}$ This plasmid belongs to an unusual incompatibility group, $\operatorname{Inc} A$, harbours a Tn7-like transposon carrying trimethoprim and streptomycin/spectinomycin resistance determin- 
Table I. Oligonucleotides employed as probes in hybridisations

\begin{tabular}{|c|c|c|c|}
\hline Gene & Oligonucleotide sequence & $\begin{array}{c}\text { Bases nos. } \\
\text { in gene }\end{array}$ & Reference \\
\hline dhfrla & 5'-CAAGTTTTACATCTGACAATGAGAACGTAT & $429-458$ & 28 \\
\hline$d h r l b$ & 5.GTTGGACATCAAATGATGACAATGTAGTTG & $197-226$ & 9 \\
\hline$d h f r V$ & 5'-CCTGGACGGCCGATAATGACAACGTAATAG & $1502-1531$ & 14 \\
\hline dhffrll & 5-GAATTTCAAGCTCAAATGAAAATGTATTAG & $790-819$ & 8 \\
\hline
\end{tabular}

ants and a Tn3-like transposon carrying ampicillin resistance determinants. Resistance to sulphamethoxazole is also mediated by pUK $28 .^{20}$

The purpose of the present study was to investigate the prevalence and nature of resistance to trimethoprim in urinary pathogens isolated in the Angus district of northern Scotland and to determine whether plasmid pUK28 was also responsible for plasmidmediated trimethoprim resistance in this area.

\section{Materials and methods}

\section{Isolation of clinical strains}

Enterobacterial isolates were cultured from midstream urine specimens containing $10^{8}$ organisms $/ \mathrm{L}$ as well as pus cells. They were collected from the diagnostic laboratory, Stracathro Hospital, Angus, between November 1987 and January 1988. All repeat specimens were excluded from the study.

\section{Characterisation and sensitivity testing}

Each isolate was identified to genus level by the MAST ID 15 system (Mast Laboratories Ltd, Merseyside). The minimum inhibitory concentration (MIC) of trimethoprim for each organism was determined by diluting a 6 -h broth culture in saline $0.9 \%$ and plating c. $40-100 \mathrm{cfu}$ on to the surface of IsoSensitest Agar plates (Oxoid) containing increasing concentrations of trimethoprim. The lowest concentration showing no visible growth after incubation for $18 \mathrm{~h}$ at $37^{\circ} \mathrm{C}$ was taken as the MIC. The sensitivity of each strain was also tested against a selection of antibacterial drugs by plating a similar dilution on to IsoSensitest agar plates containing $10 \mathrm{mg} / \mathrm{L}$ of drug, except in the cases of sulphamethoxazole and spectinomycin where $100 \mathrm{mg} / \mathrm{L}$ was used. The concentrations were chosen so that a direct comparison could be made with our earlier studies in Edinburgh, Glasgow and elsewhere.

\section{Transfer of resistance plasmids}

Bacterial strains resistant to trimethoprim $10 \mathrm{mg} / \mathrm{L}$ were tested for their ability to transfer trimethoprim resistance by the method described previously. ${ }^{19} \mathrm{Con}-$ jugation studies were performed at both $37^{\circ} \mathrm{C}$ and $30^{\circ} \mathrm{C}$ to allow detection of temperature-sensitive transferable plasmids. Escherichia coli $\mathrm{K}_{12}$ strains J53-2 (F pro met rifampicin-resistant) and $\mathrm{J} 62-1$ ( $\mathrm{F}^{-}$pro his trp nalidixic acid-resistant $)^{23}$ were employed as recipients. The $\mathrm{X}^{+}$transfer factor ${ }^{24}$ was employed for mobil- isation of non-self-transferable plasmids by a triple mating procedure described previously. ${ }^{19}$

\section{Preparation of plasmid DNA and restriction enzyme analysis}

Plasmid DNA was extracted from overnight nutrient broth cultures by the method of Birnboim and Doly $^{25}$ modified as described by Maniatis et al. ${ }^{26}$ Plasmid DNA was digested with the restriction endonuclease HindIII (Life Technologies Ltd, Paisley) according to the manufacturer's instructions. Routinely, reaction mixtures contained $10 \mu \mathrm{l}$ of plasmid DNA and 5-10 units of enzyme in a total volume of $20 \mu \mathrm{l}$. Incubation was for $1-2 \mathrm{~h}$ at $37^{\circ} \mathrm{C}$. DNA fragments were analysed and their sizes were estimated by horizontal agarose gel electrophoresis. Bacteriophage $\lambda$ DNA, digested with an appropriate restriction endonuclease, was included on each gel to provide mol. wt standards.

\section{Preparation of Southern blots and DNA hybridisation procedures}

Plasmid DNA isolated on agarose gels was depurinated, denatured, neutralised and transferred to Hybond $\mathrm{N}+$ filters (Amersham International) by the method of Southern. ${ }^{27}$ The filters were baked at $80^{\circ} \mathrm{C}$ for $2 \mathrm{~h}$ to immobilise the plasmid DNA before hybridisation. Oligonucleotide probes specific for the dhfrIa, Ib, $V$ and $V I I$ genes (table I) were $3^{\prime}$-end labelled with fluorescein-dUTP by the ECL oligolabelling system (Amersham) in conditions recommended by the manufacturer. Pre-hybridisation and hybridisation were performed at $42^{\circ} \mathrm{C}$ with hybridisation buffers recommended by Amersham. After hybridisation, the filters were washed in $2 \times$ SSC with SDS $0.1 \%$ twice for $15 \mathrm{~min}$ at room temperature and in $0.5 \times \mathrm{SSC}$ with SDS $0.1 \%$ twice for $15 \mathrm{~min}$ at $53^{\circ} \mathrm{C}$. Detection of a positive hybridisation result was by means of an ECL detection kit (Amersham) with the conditions and protocols recommended by the manufacturer. Plasmids pFE872 (dhfrla), ${ }^{28}$ pUK1121 $\left(\text { dhfrIb) }{ }^{29} \text { pLK09 (dhfrV), }{ }^{13} \text { pUK672 (dhfrVI }\right)^{30}$ and pUN1034(dhfrVII $)^{31}$ were used as controls. DNA gene probes specific for the integrase genes of $\operatorname{Tn} 7\left(\right.$ int $\left._{7}\right)$ and Tn2l (int ${ }_{21}$ ) comprised a l-7-kb Aval/ HpaI fragment of plasmid pRSS02132 and a 1.3-kb KpnI/BamHI fragment of plasmid pLK026, ${ }^{15}$ respectively. The probes were labelled with fluorescein-11-dUTP with an ECL random prime labelling kit (Amersham) and 
the conditions recommended by the manufacturer. Pre-hybridisation and hybridisation were performed at $60^{\circ} \mathrm{C}$ with hybridisation buffers recommended by Amersham. After hybridisation, filters were washed according to the manufacturer's recommendations and detection of a positive hybridisation result was by means of an ECL detection kit (Amersham) with the conditions and protocols recommended by the manufacturer.

\section{Results}

\section{Characterisation of clinical strains}

Eight hundred and forty-five strains of Enterobacteriaceae were isolated from specimens with significant bacteriuria during the period of study; of these, 417 strains were obtained from hospitalised patients and 428 from patients in the community. Escherichia coli comprised $74.7 \%$ of the total population studied; no significant difference was observed between the two populations. Proteus spp. were more prevalent amongst hospital isolates $(15.9 \%)$ than amongst community isolates $(9 \cdot 1 \%)$. Klebsiella and Enterobacter spp. comprised c. $4 \%$ and $3 \%$ of the population, respectively, in both hospital and community isolates; $6 \%$ of the isolates did not belong to any of these genera.

Each isolate was tested for resistance to a range of antimicrobial agents and the results are summarised in the figure. As expected, the prevalence of resistance to all antimicrobial agents was lower in isolates obtained from general practice than in those obtained from hospitalised patients. The prevalence of trimethoprim

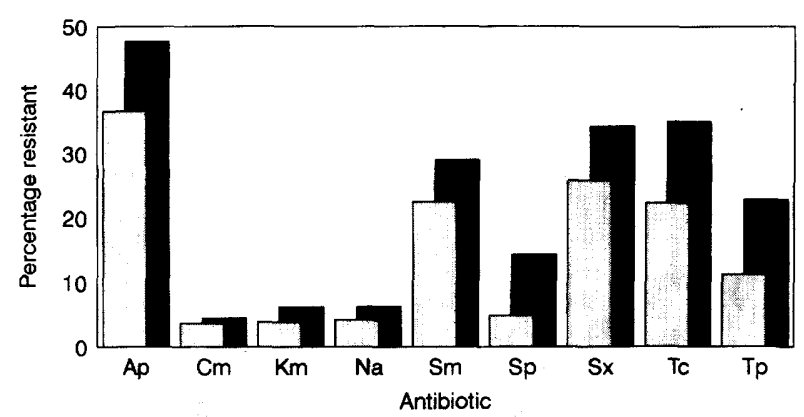

Figure. Percentage of enterobacterial pathogens resistant to antimicrobial agents. $:$, Community isolates; $\square$, hospital isolates; Ap, ampicillin; $\mathrm{Cm}$, chloramphenicol; $\mathrm{Km}$, kanamycin; $\mathrm{Na}$, nalidixic acid $;$ Sm, streptomycin; Sp, spectinomycin; Sx, sulphamethoxazole; Tc, Tetracycline; Tp, trimethoprim. resistance (MIC $>10 \mathrm{mg} / \mathrm{L})$ in hospital isolates $(22.8 \%)$ was double that found in community isolates $(11.2 \%)$. Similarly the prevalence of spectinomycin resistance within hospital isolates $(14.3 \%)$ was significantly higher than that found in community isolates $(4.9 \%)$ and may indicate an increased prevalence of Tn7-like transposons, which encode resistance to streptomycin/spectinomycin in addition to trimethoprim resistance.

\section{Characterisation of trimethoprim-resistant isolates}

The prevalence and nature of trimethoprim resistance within the two populations is summarised in table II. In both populations, E.coli accounted for $>70 \%$ of the strains studied. Proteus spp. accounted for $16 \%$ of the hospital isolates. In contrast, only $9 \cdot 1 \%$ of general practice isolates belonged to this genus. However, the increased incidence of Proteus spp. among hospital specimens did not contribute to the different overall level of trimethoprim resistance observed in the two populations. The majority of trimethoprim-resistant bacteria were found to be resistant to $1000 \mathrm{mg} / \mathrm{L}(77.9 \%$ of trimethoprimresistant hospital isolates and $81.2 \%$ of general practice isolates).

Each isolate resistant to $10 \mathrm{mg} / \mathrm{L}$ of trimethoprim was tested for the presence of transferable R-plasmids. The results (table II) show that only $23 \%$ of the resistant strains in each population transferred trimethoprim resistance. Three of the plasmids identified in hospital isolates, and one plasmid from a general practice isolate, required to be mobilised by the $\mathrm{X}^{+}$ transfer factor. In addition, one plasmid, from a general practice specimen, transferred only at the lower temperature of $30^{\circ} \mathrm{C}$. All the trimethoprim Rplasmids mediated resistance to high levels of the agent $(\mathrm{MIC}>1000 \mathrm{mg} / \mathrm{L}$ ).

\section{Characterisation of R-plasmids}

The 33 trimethoprim R-plasmids ( 22 from hospital isolates and 11 from general practice isolates) were characterised by determination of their resistance profile, molecular size and HindIII restriction endonuclease fingerprint. Seventeen different plasmid types were distinguished; eight were found exclusively within the hospital strains (table III) and five exclusively within the community isolates (table IV).

Table II. Percentage of trimethoprim resistance amongst urinary bacteria in Angus district (Nov. 1987-Jan. 1988)

\begin{tabular}{lcccc}
\hline $\begin{array}{l}\text { Source of } \\
\text { isolates }\end{array}$ & $\begin{array}{c}\text { Number } \\
\text { of strains }\end{array}$ & $\begin{array}{c}\text { Strains (\%) with MIC } \\
\text { of trimethoprim (mg/L) }\end{array}$ & $\begin{array}{c}\text { Strains with } \\
\text { trimethoprim } \\
\text { R-plasmids (\%) }\end{array}$ \\
\cline { 2 - 3 } & 417 & 22.8 & $17 \cdot 7$ & 5.3 \\
Hospitals & 428 & $11 \cdot 2$ & $9 \cdot 1$ & $2 \cdot 6$ \\
General practice & 845 & 16.9 & 13.4 & 3.9 \\
Total & & & 1000 & \\
\hline
\end{tabular}


Table III. Characteristics of trimethoprim R-plasmids from hospital isolates

\begin{tabular}{clrllllll}
\hline & & & & \multicolumn{3}{c}{ Hybridisation with specific } \\
probes
\end{tabular}

Abbreviations of resistance determinants: Ap-ampicillin; $\mathrm{Cm}-$ chloramphenicol; $\mathrm{Km}$-kanamycin; Sm-streptomycin; Sp-spectinomycin; Sx-sulphamethoxazole; $\mathrm{Tc}$-tetracycline; $\mathrm{Tp}$-trimethoprim.

Table IV. Characteristics of trimethoprim R-plasmids from community isolates

\begin{tabular}{|c|c|c|c|c|c|c|c|}
\hline \multirow{2}{*}{ Number } & \multirow{2}{*}{ Resistance pattern } & \multirow{2}{*}{ Size $(\mathbf{k b})$} & \multirow{2}{*}{$\begin{array}{l}\text { Plasmid } \\
\text { designation }\end{array}$} & \multicolumn{4}{|c|}{$\begin{array}{l}\text { Hybridisation with specific } \\
\text { probes }\end{array}$} \\
\hline & & & & dhfrIa & $d h f r I b$ & int $t_{7}$ & int $_{21}$ \\
\hline 1 & $\mathrm{ApSxTp}$ & 112 & pUK 1187 & - & + & + & _- \\
\hline 2 & ApSxTp & 12 & pUK 1276 & - & + & - & - \\
\hline 2 & SxTp & 68 & pUK 1189 & + & - & - & + \\
\hline 1 & ApSmSpSxTp & 67 & pUK 1185 & - & + & + & - \\
\hline 1 & ApSmSxTp & 123 & pUK 1274 & + & - & - & + \\
\hline 1 & ApSxTp & 71 & pUK 1279 & - & + & - & - \\
\hline 1 & $\mathrm{KmTp}$ & 67 & pUK 1278 & + & - & + & - \\
\hline 1 & SxTp & 15 & pUK 1190 & - & + & - & - \\
\hline 1 & $\mathrm{Tp}$ & 79 & pUK 1280 & + & - & - & + \\
\hline
\end{tabular}

Abbreviations as for table III.

Four plasmids, pUK1185, pUK1187, pUK1189 and pUK 1190, were found in both hospital and community isolates.

In the hospital isolates, two plasmids, pUK1184 (identified on six occasions) and pUK1185 (identified on five occasions), were found to predominate. Both plasmids harbour resistance genes for ampicillin, sulphamethoxazole and streptomycin/spectinomycin in addition to trimethoprim. Digestion of plasmid pUK1184 with the restriction endonuclease HindIII resulted in a fingerprint identical to that obtained after HindIII digestion of plasmid pUK28, previously shown to predominate in urinary pathogens isolated in Edinburgh hospitals during 1981-1986. ${ }^{19}$ Plasmid pUK 1185 showed a very similar restriction pattern, differing only in a single fragment. Plasmid pUK 1185 was also found on one occasion in a general practice isolate. In all instances where plasmid pUK1185 was isolated, the host organism was identified as $E$. coli. Four of the five E. coli strains harbouring pUK1185 were isolated from different patients resident in the same ward of a long-stay hospital, suggesting that resistance in this ward was being spread by crosscontamination with a plasmid-bearing $E$. coli. In contrast, plasmid pUK 1184 was identified in clinical strains of E. coli, Citrobacter and Proteus spp. Furthermore, the isolates were obtained from patients in four different hospitals, ruling out the possibility of cross-contamination with a resistant pathogen or Rplasmid.

\section{Characterisation of the trimethoprim resistance genes}

Southern blots of the trimethoprim R-plasmids were hybridised with oligonucleotide probes specific for the type Ia, Ib, V and VII DHFR genes. The results are summarised in tables III and IV. None of the plasmids hybridised with probes specific for the $d h f r V$ and $V I I$ genes. A total of seven plasmids hybridised with the dhfrIa oligonucleotide probe representing six different plasmid types. Twenty-three plasmids, representing nine different plasmid types and including the two endemic plasmids, pUK 1184 and pUK1185, hybridised with the $d h f r I b$ oligonucleotide probe. Three plasmids did not hybridise with any of the DHFR specific probes tested.

\section{Prevalence of $T n 7$ and Tn21 integrase genes in trimethoprim R-plasmids}

Each plasmid was tested for the presence of the $i_{n} t_{7}$ 
and int $_{21}$ integrase genes. The majority of different plasmids carrying the dhfrIa gene showed positive hybridisation with the int $_{21}$ gene probe; only one plasmid, pUK1278, hybridised with the int $t_{7}$ gene probe. This indicates that, amongst this population of trimethoprim R-plasmids, the dhfrIa gene is rarely found within a Tn7-like location and may be more associated with $\operatorname{Tn} 21$-like structures. In contrast, three different plasmids carrying the $d h f r I b$ gene showed positive hybridisation with the int t $_{7}$ gene probe, including the two endemic plasmids pUK1184 and pUK1185. Only one plasmid, pUK1191, showed positive hybridisation with the int $_{21}$ gene probe and the remaining five plasmid types harbouring the dhfrIb gene showed no hybridisation with either integrase gene probe.

\section{Discussion}

The prevalence of trimethoprim resistance amongst urinary pathogens appears to vary according to country. Most recent data indicate that trimethoprim resistance in enterobacterial urinary pathogens in northern Europe has levelled to around $12 \%$ in general practice isolates and $15-20 \%$ in hospital isolates. ${ }^{7}$ In contrast, surveys in tropical and developing countries have revealed that the prevalence of resistance to trimethoprim is very much higher than in industrialised countries, with $30-64 \%$ of urinary pathogens showing resistance to trimethoprim $10 \mathrm{mg} / \mathrm{L} .{ }^{7}$ In most areas of the world, the proportion of high-level, nontransferable resistance increased dramatically in the 1980s and this has been shown to result from the migration of trimethoprim resistance genes, carried on resistance transposons, into the bacterial chromosome. ${ }^{19-21}$

The results of this study show that resistance to trimethoprim continues to present a significant dilemma in the choice of treatment for urinary tract infections in Scotland. As might be expected, a notable difference was observed between the prevalence of resistance amongst hospital isolates than amongst those from general practice. In Scotland, studies conducted in Edinburgh during the 1980s showed that following a peak incidence of $18.3 \%$ trimethoprim resistance (MIC $>10 \mathrm{mg} / \mathrm{L}$ ) amongst hospital isolates of urinary pathogens, the incidence of resistance to trimethoprim gradually decreased to around $12 \%$ by 1984 and has remained at that level since. ${ }^{33}$ Resistance levels in the Angus district of northern Scotland are significantly higher than in Edinburgh, although as has previously been reported in clinical strains in Edinburgh and Glasgow, the majority of the highly resistant isolates were unable to transfer their resistance, ${ }^{19-21}$ suggesting that a similar migration of trimethoprim resistance transposons into the bacterial chromosome has occurred in northern Scotland.

An examination of the trimethoprim R-plasmids identified in this survey has revealed that two very closely related R-plasmids, pUK1184 and pUK1185, were responsible for the majority of transferable trimethoprim resistance in this population. Both plasmids are clearly related to plasmid pUK28, the trimethoprim R-plasmid previously shown to be endemic in Edinburgh hospital and community isolates, ${ }^{19,20}$ and illustrate the epidemic spread and persistent maintenance of a single plasmid within bacterial populations separated by relatively large geographic distances. Plasmid pUK28 was also confirmed in this study to harbour a dhfrIb gene. Hence it would appear that this gene, and not the dhfrIa gene, is the dominant trimethoprim resistance gene amongst trimethoprim R-plasmids in Scotland. Although the $d h f r I b$ gene was found to be present within Tn7-like structures on three occasions, the majority of $d h f r I b$ genes do not appear to be associated with integron structures. Thus, other mechanisms of spread of this gene, which have contributed to its widespread occurrence in trimethoprim R-plasmids in Scotland, must exist and remain to be determined.

We thank Tayside Health Board for grant no. R267.

\section{References}

1. Amyes SGB, Smith JT. R-factor trimethoprim resistance mechanism: an insusceptible target site. Biochem Biophys Res Commun 1974; 58: 412-418.

2. Young H-K, Thomson CJ. Plasmid-encoded trimethoprimresistant dihydrofolate reductases in gram-negative bacteria. J Med Microbiol 1990; 31: 7-9.

3. Parsons Y, Hall RM, Stokes HW. A new trimethoprim resistance gene, dhfr $X$, in the $\operatorname{In} 7$ integron of plasmid pDGO100. Antimicrob Agents Chemother 1991; 35: 24362439.

4. Amyes SGB, Towner KJ, Young H-K. Classification of plasmid-encoded dihydrofolate reductases conferring trimethoprim resistance. $J$ Med Microbiol $1992 ; 36: 1-3$.

5. Singh KV, Reves RR, Pickering LK, Murray BE. Identification by DNA sequence analysis of a new plasmid-encoded trimethoprim resistance gene in fecal Escherichia coli isolates from children in day-care centers. Antimicrob Agents Chemother 1992; 36: 1720-1726.

6. Barth PT, Datta N, Hedges RW, Grinter NJ. Transposition of a deoxyribonucleic acid sequence encoding trimethoprim

and streptomycin resistances from $\mathbf{R} 483$ to other replicons. $J$ Bacteriol 1976; 125 : 800-810.

7. Goldstein FW, Acar JF. Evolution and spread of trimethoprim resistance in gram-negative bacteria. $J$ Med Microbiol $1990 ; 31: 1-4$.

8. Sundström L, Swedberg G, Sköld O. Characterization of transposon Tn5086, carrying the site-specifically inserted gene dhfrVII mediating trimethoprim resistance. $J$ Bacteriol 1993; 175: 1796-1805.

9. Young H-K, Qumsieh MJ, McIntosh ML. Nucleotide sequence and genetic analysis of the type Ib trimethoprim-resistant, Tn4132-encoded dihydrofolate reductase. J Antimicrob Chemother 1994 (in press).

10. Towner KJ, Young H-K, Thomson CJ, Amyes SGB. Detection in the United Kingdom of trimethoprim-resistant Escherichia coli encoding the type V dihydrofolate reductase. Eur $J$ Clin Microbiol Infect Dis 1990; 9: 149-150.

11. Heikkila E, Sundström L, Huovinen $P$. Trimethoprim resistance in Escherichia coli isolates from a geriatric unit. Antimicrob Agents Chemother 1990; 34: 2013-2015.

12. Heikkila E, Renkonen OV, Sunila R, Uurasmaa P, Huovinen $P$ The emergence and mechanisms of trimethoprim resistance 
in Escherichia coli isolated from outpatients in Finland. J Antimicrob Chemother 1990; 25: 275-283.

13. Sundström L. Vinayagamoorthy T, Sköld O. Novel type of plasmid-borne resistance to trimethoprim. Antimicrob Agents Chemother 1987; 31 : 60-66.

14. Sundström L. Radstrom P. Swedberg G. Sköld O. Site-specific recombination promotes linkage between trimethoprimand sulfonamide resistance genes. Sequence characterization of $d h f r V$ and $s u l l$ and a recombination active locus of Tn21. Mol Gen Genet 1988; 213: 191-201

15. Sundström L, Sköld $O$. The dhfrIa trimethoprim resistance gene of $\operatorname{Tn} 7$ can be found at specific sites in other genetic surroundings. Antimicrob Agents Chemother 1990; 34: 642-650.

16. Wylie BA. Koornhof $\mathrm{HJ}$. Trimethoprim resistance in gramnegative bacteria isolated in South Africa. $J$ Antimicrob Chemother 1989; 24: 973-982.

17. Young H-K. Amyes SGB. Characterisation of a new transposon-mediated trimethoprim-resistant dihydrofolate reductase. Biochem Pharmacol 1985; 34: 4334-4337.

18. Tait S, Amyes SGB. Trimethoprim resistant dihydrofolate reductases in normal faecal flora isolated in India. Epidemiol Infect 1994 (in press)

19. Amyes SGB, Doherty CJ, Young H-K. High-level trimethoprim resistance in urinary bacteria. Eur J Clin Microbiol 1986; 5 : 287-291.

20. Amyes SGB. Trimethoprim resistance in urinary bacteria isolated from patients attending general practitioners. $A n n$ Inst Pasteur Microbiol 1987; 138 : 439-448.

21. Kraft CA, Platt DJ. Timbury MC. Distribution and transferability of plasmids in trimethoprim-resistant urinary strains of Escherichia coli: a comparative study of hospital isolates. J Med Microbiol 1984; 18: 95-105.

22. Kraft CA. Timbury MC, Platt DJ. Restriction enzyme fingerprinting of trimethoprim resistance plasmids. Epidemiol Infect 1987: $98: 241-252$.
23. Bachmann BJ. Pedigrees of some mutant strains of Escherichia coli K-12. Bacteriol Rev 1972; 36: 525-557.

24. Sharma PL, Sharma KB, Prakash K. Incidence of conjugative plasmid amongst multidrug resistant Salmonella typhimurium strains isolated from different parts of India (1979-1982). Indian J Med Res 1984; 79 : 473-478.

25. Birnboim HC, Doly J. A rapid alkaline extraction procedure for screening recombinant plasmid DNA. Nucleic Acids Res $1979 ; 7: 1513-1523$.

26. Maniatis T, Fritsch EF, Sambrook J. Molecular cloning. A laboratory manual. Cold Spring Harbor, NY, Cold Spring Harbor Laboratory, 1982.

27. Southern EM. Detection of specific sequences among DNA fragments separated by gel electrophoresis. $J \mathrm{Mol} \mathrm{Biol}$ 1975; 98: 503-517

28. Fling $\mathrm{ME}$, Richards $\mathrm{C}$. The nucleotide sequence of the trimethoprim resistant dihydrofolate reductase gene harbored by Tn7. Nucleic Acids Res 1983; 11: 5147-5158.

29. Qumsieh MJ, Young H-K. Cloning of the type Ib trimethoprim-resistant dihydrofolate reductase gene and preparation of a specific biotinylated DNA probe. $J$ Antimicrob Chemother 1991; 27: 707-712.

30. Wylie BA, Amyes SGB, Young H-K, Koornhof HJ. Identification of a novel plasmid-encoded dihydrofolate reductase mediating high-level resistance to trimethoprim. $J$ Antimicrob Chemother 1988; 22: 429-435.

31. Towner KJ, Carter GI. Cloning of the type VIl trimethoprimresistant dihydrofolate reductase gene and identification of a specific DNA probe. FEMS Microbiol Lett 1990; 58: 19-22.

32. Steen R, Sköld O. Plasmid-borne or chromosomally mediated resistance by $\operatorname{Tn} 7$ is the most common response to ubiquitous use of trimethoprim. Antimicrob Agents Chemother 1985; 27 : 933-937.

33. Thomson CJ, Paton RH, Hood J, Miles RS, Amyes SGB. Antibiotic resistance in urinary bacteria isolated in central Scotland. Int J Antimicrob Agents 1992; 1: 223-228. 